\title{
Modeling the properties of plasmaspheric hiss: 2. Dependence on the plasma density distribution
}

\author{
Lunjin Chen, ${ }^{1}$ Jacob Bortnik, ${ }^{1}$ Wen Li, ${ }^{1}$ Richard M. Thorne, ${ }^{1}$ and Richard B. Horne ${ }^{2}$ \\ Received 26 September 2011; revised 1 February 2012; accepted 1 March 2012; published 1 May 2012.
}

[1] Wave propagation plays an important role in linking the chorus source in the plasma trough region and the hiss emission in the plasmasphere. We investigate the dependence of plasmaspheric hiss on the background plasma density, which essentially controls the evolution of chorus after its generation at MLT $=10$. The variation of plasma density under study includes variation of the location and width of the plasmapause, and the variation of the density distribution in the trough. We demonstrate that the plasmapause shape does not affect the peak hiss intensity significantly, but it does regulate the hiss intensity near the field-aligned direction. As the plasmasphere contracts or the plasmapause width increases, the field-aligned component of plasmaspheric hiss become relatively more intense, as does the intensity of hiss in the inner region, although the peak hiss intensity remains about the same. The trough density distribution, on the other hand, directly influences the accessibility of chorus rays into plasmasphere, and therefore plays an important role in the peak hiss intensity. As the density gradient in the plasma trough increases toward the plasmasphere, the resulting peak in the hiss intensity can increase by up to $10 \mathrm{~dB}$.

Citation: Chen, L., J. Bortnik, W. Li, R. M. Thorne, and R. B. Horne (2012), Modeling the properties of plasmaspheric hiss: 2. Dependence on the plasma density distribution, J. Geophys. Res., 117, A05202, doi:10.1029/2011JA017202.

\section{Introduction}

[2] Plasmaspheric hiss is a naturally occurring broadband incoherent emission, mostly confined to the plasmasphere [e.g., Thorne et al., 1973] and the high-density plume region [e.g., Summers et al., 2008], with frequency typically in the range of $200 \mathrm{~Hz}$ to $2 \mathrm{kHz}$. Although several ideas have been proposed to account for the origin of hiss, there is increasing evidence [e.g., Bortnik et al., 2009; Wang et al., 2011] that the source of hiss inside the plasmasphere is a result of the evolution of discrete coherent chorus emissions, which are generated outside the plasmapause due to a cyclotron resonant instability with anisotropic electrons in the range of a few to tens of $\mathrm{keV}$ [e.g., Jordanova et al., 2010] and then subsequently propagate into the plasmasphere [Bortnik et al., 2008]. Both hiss and chorus have been recognized as playing important roles in controlling radiation belt dynamics and their quasi-equilibrium structure. Hiss is responsible for the loss of energetic electrons within the plasmasphere and in high density plumes [e.g., Lyons et al., 1972; Lyons and Thorne, 1973; Abel and Thorne, 1998a, 1998b; Albert, 2005; Summers et al., 2008], and chorus contributes to both loss and acceleration in the outer radiation belt [e.g., Li et al., 2007; Lorentzen et al., 2001; Thorne et al., 2005; Xiao et al., 2009].

\footnotetext{
${ }^{1}$ Department of Atmospheric and Oceanic Sciences, University of California, Los Angeles, California, USA.

${ }^{2}$ British Antarctic Survey, Natural Environment Research Council, Cambridge, UK.

Copyright 2012 by the American Geophysical Union. 0148-0227/12/2011JA017202
}

[3] Wave propagation in the magnetospheric medium plays an essential role in linking the two emissions [Bortnik et al., 2008]. One of the key properties that controls the characteristics of wave propagation is the density distribution of cold plasma (electrons and ions in the eV energy range with thermal speed much less than the phase speed of the waves of interest). The plasmapause, a sharp boundary separating the high density plasmasphere $\left(>\sim 100 \mathrm{~cm}^{-3}\right)$ and the low density trough region $\left(<\sim 10 \mathrm{~cm}^{-3}\right)$, has been recognized as a critical component in controlling the propagation characteristics and also the excitation of plasma waves in the magnetospheric medium. Examples of the effects include preferential excitation of EMIC waves along the plasmapause [Horne and Thorne, 1993; Chen et al., 2009b, 2010], ground accessibility of chorus wave along the plasmapause [Golden et al., 2010], equatorial accessibility of auroral kilometric radiation (AKR) controlled by the size of plasmapause [Green et al., 1977; Xiao et al., 2007], azimuthal propagation of equatorially confined magnetosonic waves guided along the plasmapause [Kasahara et al., 1994], and more relevant to the present study, the trapping of chorus waves inside the plasmasphere [Bortnik et al., 2008].

[4] There are a great number of theoretical and observational studies dealing with the structure and variability of the plasma density in the magnetosphere (see recent review papers by Sandel et al. [2003], Reinisch et al. [2009], and Singh et al. [2011]). For example, the size of the plasmasphere (or plasmapause) decreases with increasing geomagnetic activity [e.g., Grebowsky, 1970; Chappell et al., 1970]. The dynamical evolution of the plasmasphere is a complicated process involving dayside refilling from the ionosphere 
balanced by nightside drainage to the ionosphere [e.g., Carpenter and Park, 1973], and modulated by the variability of the convection electric field [e.g., Grebowsky, 1970; Spasojević et al., 2003; Goldstein et al., 2002]. There are cases where the 'classic' isolated sharp density gradient plasmapause does not exist [Moldwin et al., 2002], and a smooth transition from plasmasphere-like high density to trough-like low density, also known as plamsaspheric boundary layer (PBL) [Carpenter and Lemaire, 2004], is often observed. The PBL provides a favorable condition for observing correlation of the chorus emission and the hiss emission inside the plasmasphere [Wang et al., 2011]. Recent plasmasphere studies revealed a number of structures inside and along its boundary, such as a density trough within the plasmasphere [Fu et al., 2010], and a plasmaspheric shoulder in the morning sector [e.g., Goldstein et al., 2002]. Variability of trough densities is also observed in various spacecraft measurements [e.g., Carpenter and Anderson, 1992; Sheeley et al., 2001], and is strongly dependent on the state of convection electric field [Harris, 1974]. The radial variation of the equatorial trough density scales typically as $L^{-5}$ in the midnight-noon sector and $L^{-3}$ in the noon-midnight sector [Poulter et al., 1984]. Trough densities at low altitudes also show a seasonal variation even during geomagnetically quiet times [Kitamura et al., 2009].

[5] Chorus is typically generated in the low-density trough region, and subsequently propagates away from the equator before entering the plasmasphere at high latitudes. Density gradients in the trough and near the plasmapause can affect the entry of chorus waves into the plasmasphere. The motivation of this study is to examine how the variability of the plasmapause and trough density could affect the properties of hiss inside the plasmasphere. The response of hiss to changes in the chorus source distribution has been investigated for a single prescribed plasma density distribution in a companion paper by Chen et al. [2012] (hereinafter referred to as paper I). The present study is organized as follows. In section 2 , the plasma density model used in the present study is described. The ray tracing model for hiss spectrum is presented in section 3 . The simulation results on the relationship between hiss and the density distribution are shown in section 4 , followed by conclusions in section 5 and a discussion in section 6 .

\section{Cold Plasma Density Model}

[6] To study wave propagation in the inhomogeneous magnetosphere, we use a ray tracing code HOTRAY [Horne, 1989] to follow the trajectories of a large group of rays from their source region in the plasma trough. Ray tracing requires analytic models of the magnetic field (dipole field) and the plasma density. A simple but realistic and analytic plasma density distribution, which allows control of the shape of the plasmapause and the variability of the trough, representative of the dayside region (MLT=10) is described in section 3 of paper I. Here we describe the density model briefly and emphasize description of interest for the present study.

[7] The density distribution is constructed as follows:

$$
N=N_{i}+N_{\mathrm{ps}}(1-g(L))+N_{\text {tr }} g(L)
$$

where the characteristic plasma populations in the ionosphere $\left(N_{i}\right)$, the plasmasphere $\left(N_{\mathrm{ps}}\right)$ and the trough $\left(N_{\mathrm{tr}}\right)$, are specified and analytically connected, as is required for ray tracing. $g(L)$ controls the shape of the plasmapause (the transition from the plasmasphere to the trough), defined as,

$$
g(L)= \begin{cases}1 & \text { if } L \geq L_{\mathrm{ppo}} \\ \exp \left(-\left(\frac{L-L_{\mathrm{ppo}}}{L_{\mathrm{ppw}}}\right)^{2}\right) & \text { otherwise }\end{cases}
$$

where $L_{\mathrm{ppo}}$ is the outer edge of the plasmapause, and $L_{\mathrm{ppw}}$ represents its width.

[8] The plasma trough density $N_{\text {tr }}$ is modeled as:

$$
N_{\text {tr }}(L, r)=n_{\mathrm{etr}}(L)\left(\frac{L}{r}\right)^{\alpha_{\mathrm{tr}}(L)},
$$

where the equatorial density in the plasma trough is $n_{\mathrm{etr}}(L)=13200 L_{\mathrm{ppo}}^{-4.5}\left(L / L_{\mathrm{ppo}}\right)^{\beta} \mathrm{cm}^{-3}$, which yields the trough density at the outer edge $L=L_{\text {ppo }}$ according to Carpenter and Anderson [1992] and also allows for the variation of the trough density slope $\beta . \alpha_{\text {tr }}(L)$ is chosen such that $N_{\mathrm{tr}}(L, r=1)=n_{0 \mathrm{tr}}$, independent of $L$, i.e., $N_{\mathrm{tr}}$ tends to merge toward $n_{0 \text { tr }}$ at $r=1$ along any field line in the plasma trough. $n_{0 \text { tr }}$ is an approximate measure of the trough base density just above the topside ionosphere and determines the latitudinal variation of trough density along a given field line. For example, $n_{0 \mathrm{tr}}=500 \mathrm{~cm}^{-3}$ gives $\alpha_{\mathrm{tr}} \sim 2.5$, a value typical of the plasma trough [Denton et al., 2002].

[9] In summation, there are four free parameters yet to be specified in our density model, $L_{\mathrm{ppo}}, L_{\mathrm{ppw}}, \beta$, and $n_{0 \text { tr. }}$. The first two control the location and width of the plamsapause respectively, while the last two determine the equatorial variation and latitudinal variation along a field line of the plasma density in the trough region respectively. As in our companion paper, we choose $L_{\mathrm{ppo}}=4.5, L_{\mathrm{ppw}}=0.7$, $\beta=-4.5$, and $n_{0 \text { tr }}=500 \mathrm{~cm}^{-3}$ as the nominal case, whose density distribution is shown in Figures 1c and 1d (the two are identical). Also shown are density distributions of cases similar to the nominal case, but having one of the four parameters being varied $L_{\mathrm{ppo}}=3.5$ (Figure 1a), $L_{\mathrm{ppw}}=3.0$ (Figure 1e), $\beta=-5$ (Figure $1 \mathrm{~b}$ ), and $n_{0 \mathrm{tr}}=5000 \mathrm{~cm}^{-3}$ (Figure 1f). Our adopted model allows us to vary the plasmapause shape, including the width and location, without affecting the trough density model, and thus enabling us to isolate the effect of the plasmapause alone on the hiss spectrum. We can also isolate the effect of the equatorial density distribution and latitudinal variation in the trough without changing the plasma density inside the plasmapause $L \leq L_{\mathrm{ppo}}$. Note that no appreciable difference is seen between Figures $1 \mathrm{~b}(\beta=-5)$ and $1 \mathrm{~d}(\beta=-4.5)$, since the change of the trough density at the same equatorial location is less than $1 \mathrm{~cm}^{-3}$. However, the increase in trough density slope $(|\beta|)$ can result in significant intensification of the hiss emission as shown in section 4 .

\section{Ray Tracing Model}

[10] The methodology of modeling the hiss spectrum is based on a ray tracing technique, explained in detail in our previous works [Bortnik et al., 2011b; Chen et al., 2012]. We launch a set of rays from the equator outside the plasmapause 


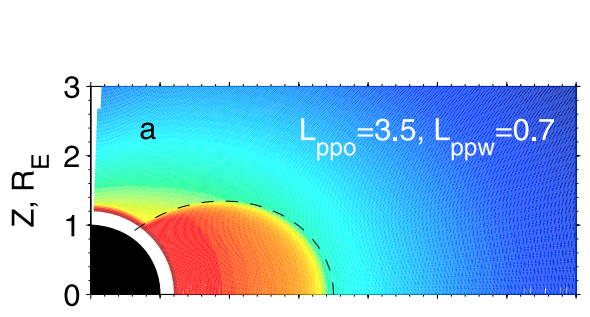

$$
\mathrm{N}_{\mathrm{e}}\left[\mathrm{cm}^{-3}\right]
$$
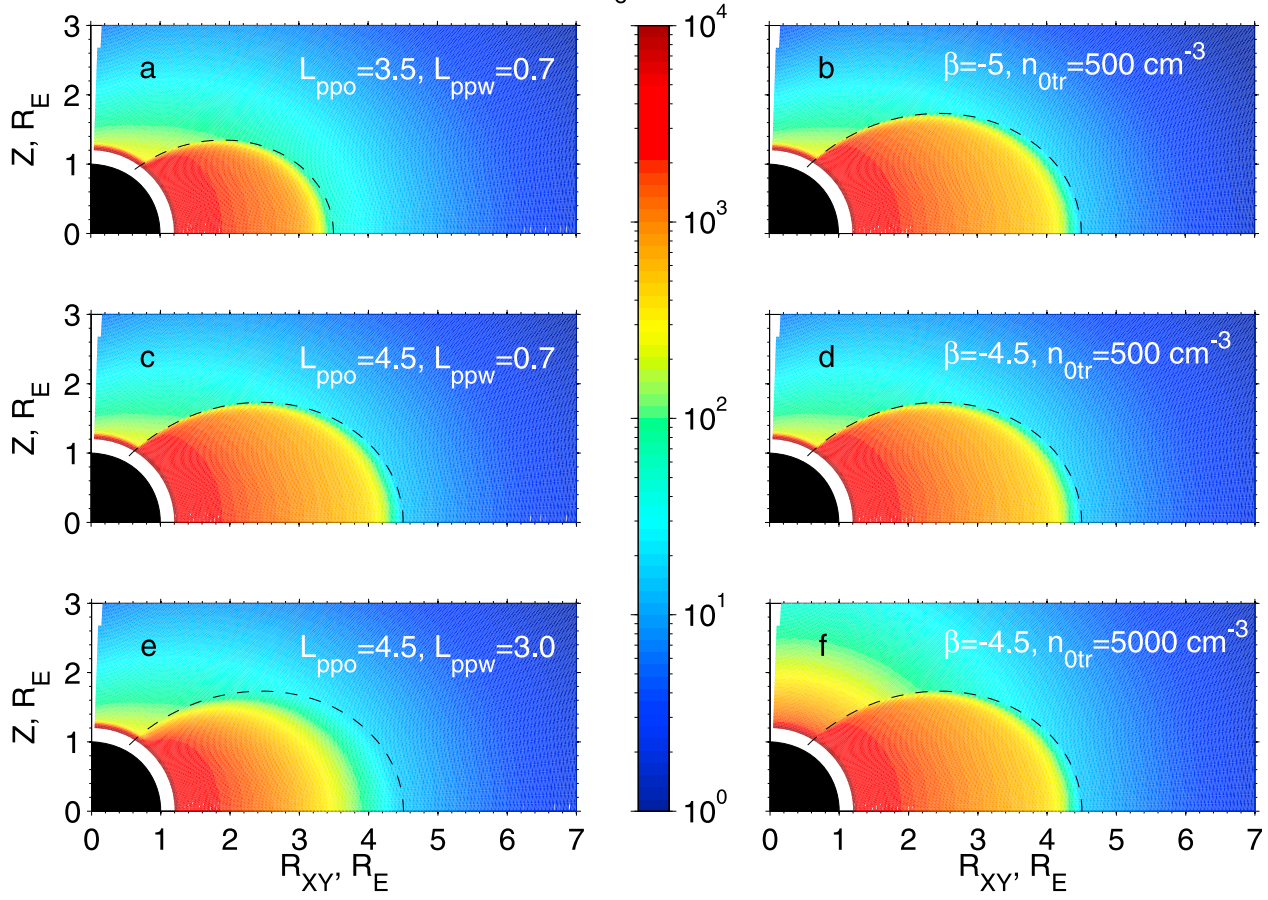

Figure 1. Density model in the meridian plane with different parameters. (c and d) The nominal density model is chosen such that $L_{\mathrm{ppo}}=4.5, L_{\mathrm{ppw}}=0.7, \beta=-4.5$ and $n_{0 \mathrm{tr}}=500 \mathrm{~cm}^{-3}$. Density distributions with different value of one of these four parameters are also shown: (a) $L_{\mathrm{ppo}}=3.5$, (e) $L_{\mathrm{ppw}}=3.0$, (b) $\beta=-5$, and (f) $n_{0 t r}=5000 \mathrm{~cm}^{-3}$. The black dashed lines indicate the field line at the outer edge of the plasmapause $L=L_{\mathrm{ppo}}$.

at a range of $L$-shell $L_{i}$ with a range of initial wave frequency $f_{i}$ and normal angle $\psi_{i}$, to represent the distribution of excited chorus rays. For any density model specified by a combination of the four parameters $\left(L_{\mathrm{ppo}}, L_{\mathrm{ppw}}, \beta\right.$, and $\left.n_{0 \mathrm{tr}}\right)$, totally $\sim 10^{5}$ rays are traced. Each chorus ray is assigned with an initial power according to

$$
\begin{aligned}
\Delta P_{w}\left(L_{i}, f_{i}, \psi_{i}\right)= & B_{w}^{2}\left(L_{i}\right) A_{L} \exp \left(-\frac{\left(X_{i}-X_{m}\right)^{2}}{X_{w}^{2}}\right) \\
& \cdot \exp \left(-\frac{\left(f_{i}-f_{m}\right)^{2}}{f_{w}^{2}}\right) \Delta L \Delta f \Delta \psi,
\end{aligned}
$$

where $X_{i}=\tan \psi_{i}, X_{m}=\tan \psi_{m}, X_{w}=\tan \psi_{w}, \psi_{m}$ and $\psi_{w}$ represent the wave normal peak and width respectively, $f_{m}$ and $f_{w}$ are the frequency peak and width respectively, and $A_{L}$ is the normalization factor such that

$$
A_{L} \int_{f_{1}}^{f_{2}} d f \int d \psi \exp \left(-\frac{\left(X_{i}-X_{m}\right)^{2}}{X_{w}^{2}}\right) \exp \left(-\frac{\left(f_{i}-f_{m}\right)^{2}}{f_{w}^{2}}\right)=1
$$

with $f_{1}$ and $f_{2}$ denoting the lower and upper cutoff frequencies of the lower band chorus respectively. The spatial distribution of wave magnetic field amplitudes $B_{w}(L)$ is chosen to be of Gaussian form,

$$
B_{w}(L)=B_{\text {peak }} \exp \left(-\frac{\left(L-L_{\text {peak }}\right)^{2}}{L_{w}^{2}}\right) .
$$

The chorus source distribution (equations (4) and (6)) in the present study is chosen as $L_{\text {peak }}=7, L_{w}=1.5, L_{\text {peak }}=100 \mathrm{pT}$, $\psi_{m}=0^{\circ}, \psi_{w}=45^{\circ}, f_{m}=0.25 f_{\text {ce }}, f_{w}=0.15 f_{\text {ce }}, f_{1}=0.1 f_{\text {ce }}$, and $f_{2}=0.5 f_{\text {ce }}$ (see paper I).

[11] In addition to wave propagation, the wave Landau damping is also evaluated by using suprathermal electron $(0.1-10 \mathrm{keV})$ distributions at MLT $=10$ based on THEMIS observations as discussed in section 2 of paper I. Based on our tracing of the raypath, wave normal, and wave power of all rays, we reconstruct the wave power, $P_{w}(L, \lambda, f, \psi)$ in unit of $\mathrm{pT}^{2} / \mathrm{Hz} / \mathrm{deg}$, as a function of spatial coordinates $L$ and latitude $\lambda$, wave normal angle $\psi$ and wave frequency $f$, according to the method described by Bortnik et al. [2011b].

[12] A key piece of understanding that is important for linking chorus and hiss is knowledge of how the chorus rays access the plasmapause, which provides the seed emission that is subject to subsequent evolution inside the plasmasphere. Figure 2 shows ray tracing of chorus rays launched in the nominal density distribution at $L=6$ with frequency $f=$ $0.15 f_{\text {ce }}$ and a full range of northward pointing wave normals $\left(\cos \left(\psi_{i}\right)>\cos \left(\psi_{\text {res }}\right)\right.$, where the resonance cone $\left.\psi_{\text {res }} \sim 81^{\circ}\right)$ at $\mathrm{MLT}=10$. Note that positive and negative signs of $\psi$ denote anti-Earthward and Earthward pointing wave normals, respectively. Only the northward portion of the raypath prior to the first equatorial crossing is shown and the rays are separated into four groups according to the characteristics of the raypaths. The first group of rays with $-81^{\circ} \leq \psi_{i} \leq-68^{\circ}$ (Figure 2a) never reach the plasmapause and do not contribute to the hiss intensity. The waves are either attenuated 

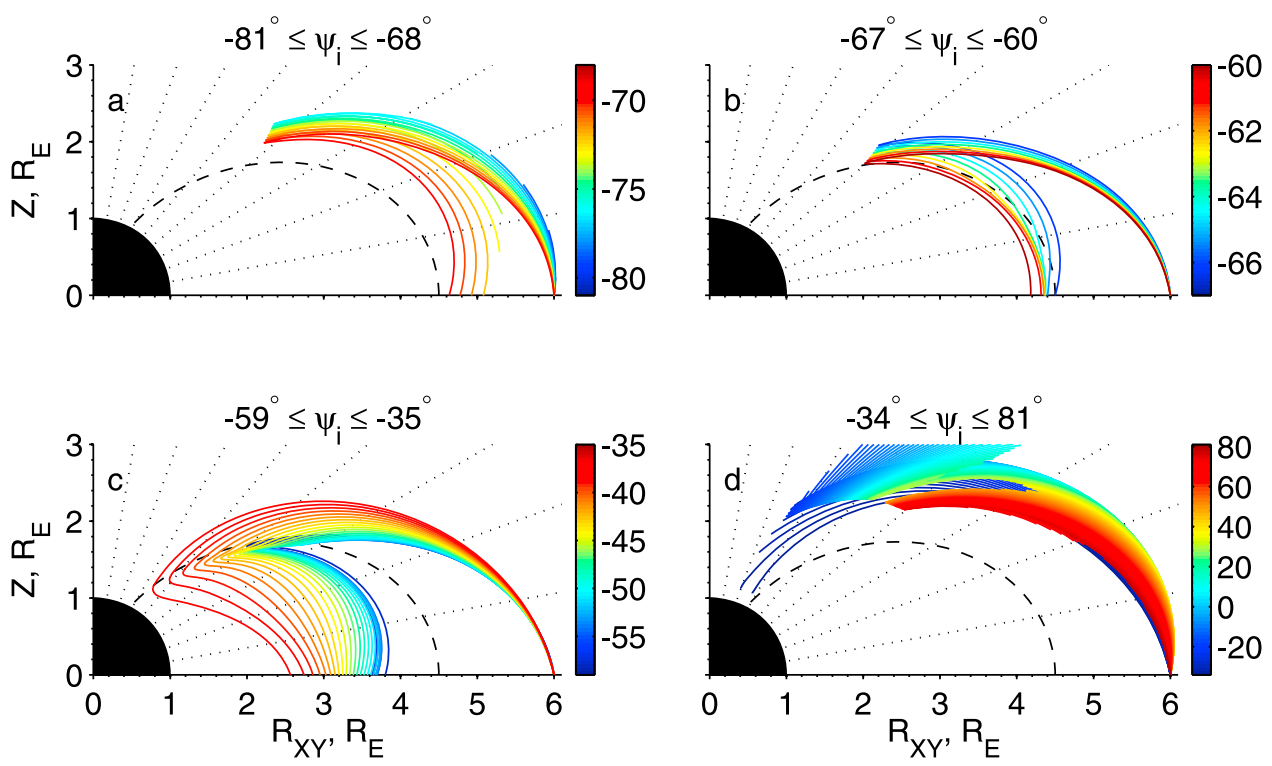

Figure 2. Examples of ray trajectories in the nominal density model $\left(L_{\mathrm{ppo}}=4.5, L_{\mathrm{ppw}}=0.7, \beta=-4.5\right.$, and $n_{0 t r}=500 \mathrm{~cm}^{-3}$, as shown in Figures $1 \mathrm{c}$ and $1 \mathrm{~d}$ ), launched at $L=6$ with $f=0.15 f_{\text {ce, }}$, divided into four groups of initial wave normal angle range: (a) $-81^{\circ} \leq \psi_{i} \leq-68^{\circ}$, (b) $-67^{\circ} \leq \psi_{i} \leq-60^{\circ}$, (c) $-59^{\circ} \leq \psi_{i} \leq-35^{\circ}$, and (d) $-34^{\circ} \leq \psi_{i} \leq 81^{\circ}$. $\psi_{i}$, in units of degree, is color-coded. Only a portion of the ray trajectories before the first equatorial crossing since launch are shown. The black dashed line indicates the field line at the outer edge of plasmapause $L=L_{\text {ppo }}=4.5$. Eight dotted lines represent the constant latitudes from $10^{\circ}$ to $80^{\circ}$ in $10^{\circ}$ spacing.

by strong Landau damping due to oblique propagation, or their propagation paths do not reach the plasmapause. The second group of rays with $-67^{\circ} \leq \psi_{i} \leq-60^{\circ}$ (Figure $2 \mathrm{~b}$ ) can reach the plasmapause, but the rays perform magnetospheric reflections (i.e., passage of $\psi= \pm 90^{\circ}$ ) before the plasmapause crossing (i.e., crossing $L=L_{\text {ppo }}$ ), which occurs at lower latitudes for higher initial wave normal angles $\psi_{i}$ (less negative). After reflection, these rays propagate more or less along the plamaspause. Although some of these rays can propagate into the plasmasphere after reflection on the southern hemisphere, the amount of power these rays carry is relatively weaker than the third group rays mentioned below, because of the weaker initial wave power, which originates at very oblique initial wave normal angles (that are weighted more weakly in our model), and stronger damping due to longer exposure outside the plasmasphere. The third group of rays $-59^{\circ} \leq \psi_{i} \leq-35^{\circ}$ (Figure $2 \mathrm{c}$ ) cross the plasmapause at $\lambda>\sim 40^{\circ}$ followed by magnetospheric reflections inside the plasmasphere. Their plasmapause passage occurs generally at higher latitudes for less negative initial wave normal angles $\psi_{i}$. This group of rays, especially those with less oblique initial wave normal and thus greater initial wave power, are the dominant contributor to the hiss emission inside the plasmasphere through entry at high latitude into the plasmasphere, which is consistent with earlier observations [Russell et al., 1969] that initially suggested that the high latitude region $\left(\sim 45^{\circ}\right)$ was the source of the steady hiss noise. The $L$ range where these chorus rays first cross the equator is limited to $2.5<L<3.5$, instead of occurring over the entire $L$ range inside the plasmasphere. However, as pointed out in paper I, the plasmaspheric hiss observed at other locations is due to the multiple bounces occurring subsequently within the plasmasphere [Bortnik et al., 2011a]. The fourth group of rays $\psi_{i} \geq-34^{\circ}$ (Figure $2 \mathrm{~d}$ ) do not access to the plasmapause but instead undergo magnetospheric reflections to higher $L$-shells.

\section{Hiss Response to Cold Plasma Density Distribution}

[13] The response of hiss to the variation of chorus distribution (the input of magnetospheric system), including spatial, frequency and wave normal angle distribution, has been investigated in paper I in a magnetosphere with a prescribed cold plasma density model. In the present study, we examine the response of hiss to the change in the cold plasma density distribution with a typical chorus distribution prescribed by observations. As in paper I, we focus on the equatorial emission $\left(\lambda=0^{\circ}\right)$, defining the emission inside the plamasphere $\left(L<L_{\text {ppo }}\right)$ as hiss and the emission outside the plasmapause as chorus.

\subsection{Plasmapause Boundary}

[14] The location of the plasmapause depends on the level of geomagnetic activity. As geomagnetic activity increases, the outer portion of plasma is stripped away toward the dayside due to enhanced convection, and the location of the plasmapause consequently moves Earthward. The response of hiss to variation in the location of the plasmapause is investigated by varying $L_{\mathrm{ppo}}$, which represents the outer edge of the plasmapause. Figure 3 shows the equatorial plasma density distribution (Figure $3 \mathrm{a}$ ), and the simulated equatorial wave amplitude (Figure 3b). As the plasmapause moves inward, the peak hiss wave intensity also shifts toward the Earth. To compare the resulting hiss, we define a gain, $G_{p}$, 

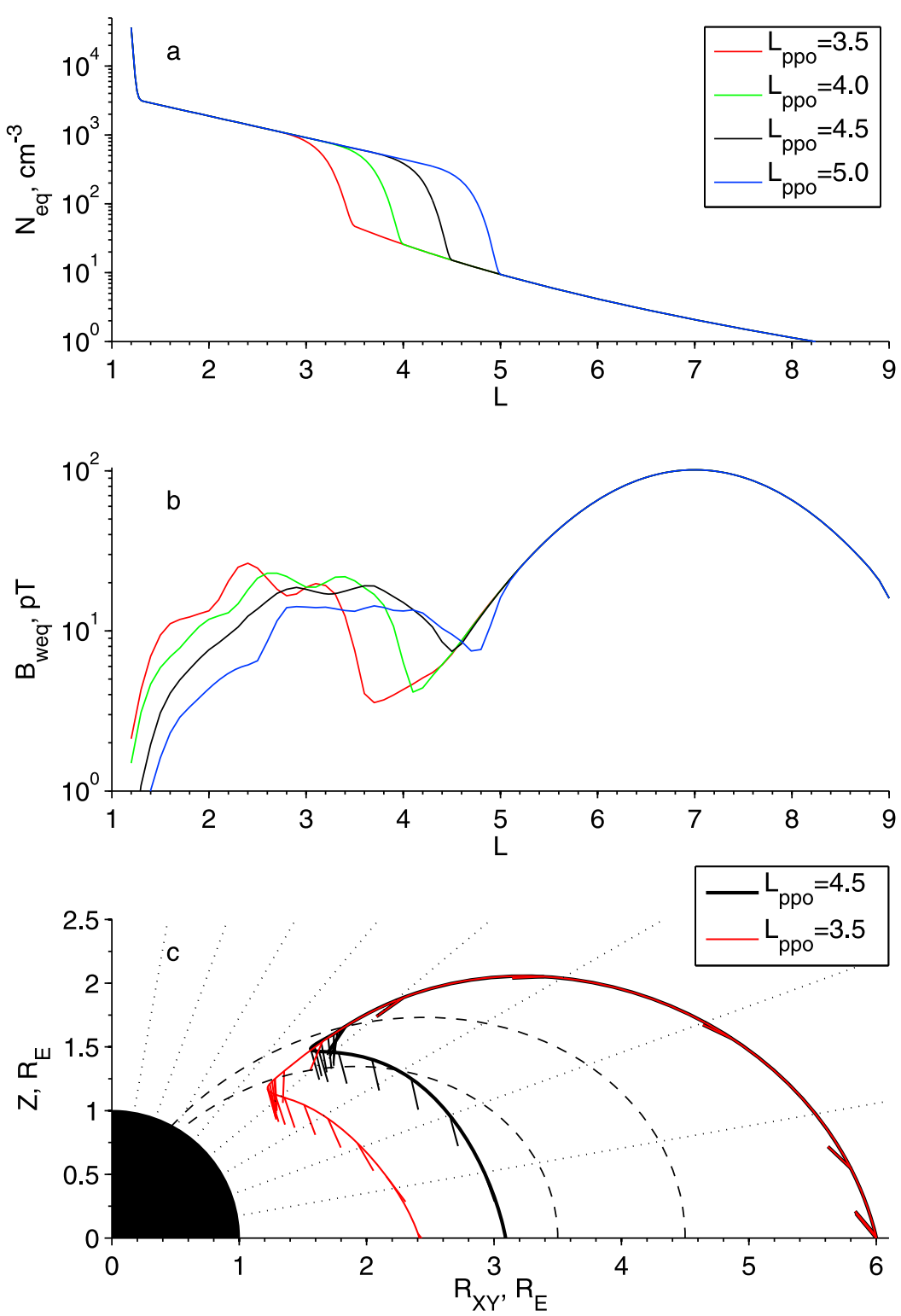

Figure 3. (a) Equatorial plasma density with a varying outer edge of the plasmapause $L_{\text {ppo }}$. (b) The corresponding equatorial wave amplitude from the simulation. (c) Example of ray tracing of the same ray, launched at $L_{i}=6$ with $\psi_{i}=-40^{\circ}$ and $\left(f / f_{\mathrm{ce}}\right)=0.15$, in density models with different values of $L_{\mathrm{ppo}}$. Field lines with $L=3.5$ and $L=4.5$ are shown as a black dashed lines. The short straight line segments along the ray trajectories indicate the directions of the wave vector during the propagation. Eight dotted lines represent constant latitudes from $10^{\circ}$ to $80^{\circ}$ in $10^{\circ}$ increments.

which measures the ratio of peak hiss intensity to that for the nominal density distribution,

$$
G_{p}=10 \times \log _{10} \frac{\text { Peak hiss intensity }}{P_{n}} \text {, in dB, }
$$

where $P_{n}$ is the peak hiss intensity $\left(366 \mathrm{pT}^{2}\right)$ for the nominal density distribution (black line in Figure $3 \mathrm{~b}$ ) and $G_{p}=0 \mathrm{~dB}$ for the nominal density distribution. The peak hiss intensity does not change significantly due to the change in the plasmapause, $G_{p}=+2.8 \mathrm{~dB}\left(B_{\text {peak }}=26 \mathrm{pT}\right)$ for $L_{\mathrm{ppo}}=3.5, G_{p}=$ $1.6 \mathrm{~dB}\left(B_{\text {peak }}=23 \mathrm{pT}\right)$ for $L_{\mathrm{ppo}}=4.0$, and $G_{p}=-2.5 \mathrm{~dB}$ $\left(B_{\text {peak }}=14 \mathrm{pT}\right)$ for $L_{\mathrm{ppo}}=5$. It should be kept in mind that $G_{p}$ does not measure the intensification or suppression of hiss intensity at any fixed $L$-shell. It is clearly shown in Figure $3 \mathrm{~b}$ that the intensification at $L=2.4$ can be up to $12.7 \mathrm{~dB}$, compared with $\sim 6 \mathrm{pT}$ in the case of $L_{\mathrm{ppo}}=5$ (blue line) and $\sim 26 \mathrm{pT}$ in the case of $L_{\mathrm{ppo}}=3.5$ (red line). The motion of the plasmapause could therefore lead to variability of the hiss intensity in the inner plasmasphere by an order of magnitude or more.

[15] The inward shifting of the hiss wave power can be explained by examining the behavior of rays with the same initial chorus conditions (launched at $L_{i}=6, \psi_{i}=-40^{\circ}$, and $f_{i}=0.15 f_{\mathrm{ce}}$ ), in models having different plasmapause locations, $L_{\mathrm{ppo}}=4.5$ (black line in Figure 3c) and $L_{\mathrm{ppo}}=3.5$ (red line in Figure 3c). As expected, the raypaths and wave vectors along the raypath in the trough regions are identical for 

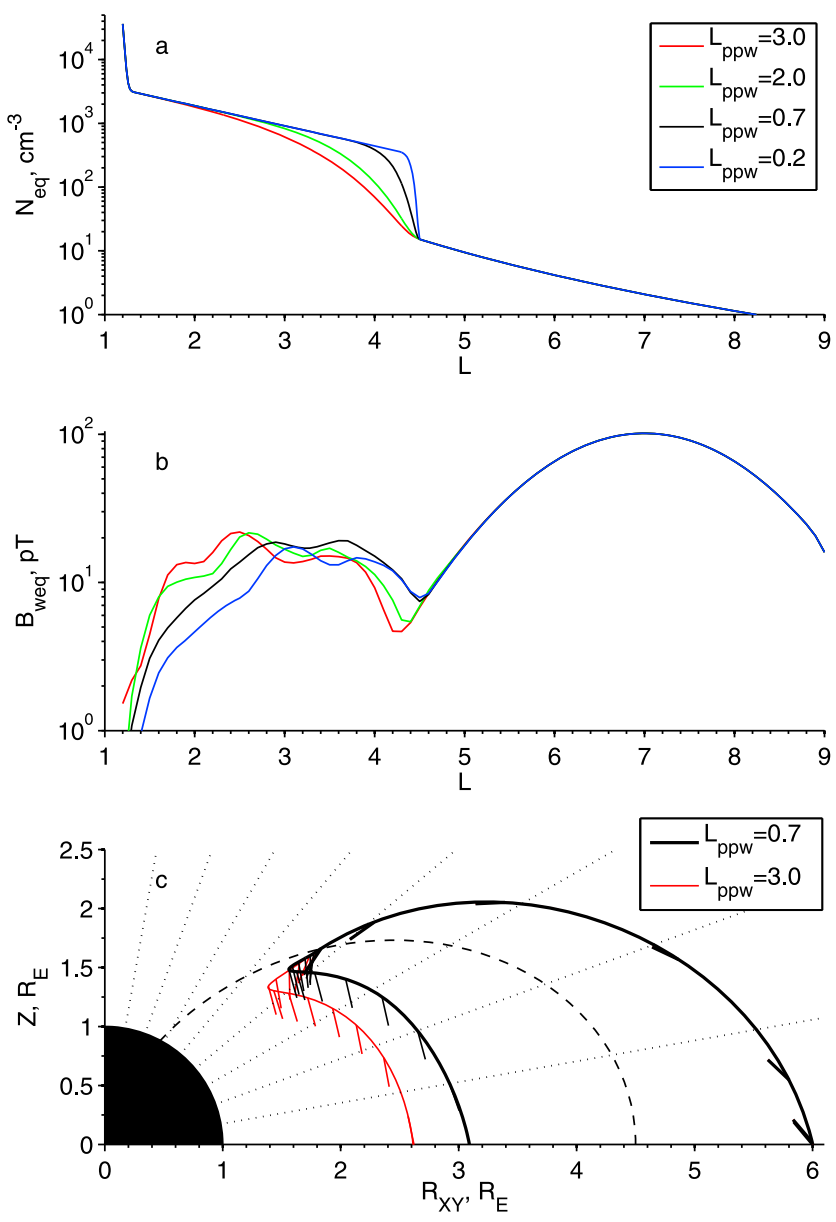

Figure 4. Similar to Figure 3 except varying the plasmapause width $L_{\mathrm{ppw}}$. The dashed line in Figure $4 \mathrm{c}$ indicates the field line $L=L_{\mathrm{ppo}}=4.5$.

both cases, as the ray propagates toward higher latitude and the Earth before reaching $L=4.5$. However, for the case $L_{\text {ppo }}=4.5$ the ray reaches the plasmapause earlier and at lower latitude than the ray for the case with $L_{\mathrm{ppo}}=3.5$. The $L_{\mathrm{ppo}}=4.5$ ray rotates its wave normal direction toward the high density plasmasphere due to the density gradient of the plasmapause, according to Snell's law. Following the magnetospheric reflection when $f<f_{1 \mathrm{hr}}$, where the wave normal angles pass through $90^{\circ}$, the ray propagates toward the equator, finally reaching the equator at $L \sim 3.1$. In contrast, with $L_{\mathrm{ppo}}=3.5$, the ray continues to propagate after $L=4.5$, experiences the plamaspause density gradient at higher latitude and lower L, and subsequently reflects and returns to the equator at lower $L$-shell, namely $L=2.4$. Erosion of the plasmasphere ensures a plasmapause crossing at higher latitudes and lower $L$-shells, resulting in equatorial crossings at lower $L$, and hence an Earthward shift of the hiss intensity on the first equatorial crossing, which controls the inner peak of the two peak structure (see paper I). Therefore, an Earthward shift of the inner peak of the equatorial hiss intensity is seen in Figure $3 \mathrm{~b}$, as $L_{\mathrm{ppo}}$ decreases.

[16] The plasmapause width also shows a strong dependence on geomagnetic activity as well as local time with the broadest transition occurring near dusk, especially in the presence of the afternoon plume [e.g., Carpenter and
Anderson, 1992]. In such cases, a plasmasphere boundary layer type transition instead of a 'classic' sharp boundary plasmapause is often observed [Moldwin et al., 2002]. The effect of such variability of the plasmapause width on hiss intensity is examined. Figure $4 \mathrm{a}$ shows the equatorial density distribution with the same outer edge $\left(L_{\mathrm{ppo}}=4.5\right)$ but different widths of the plasmapause. The widest plasmapause $L_{\mathrm{ppw}}=3$ is the case where there is a smooth density transition between plasmaspheric type plasma and trough type plasma (red line in Figures 4a and 1e), representing the plasmasphere boundary layer [Carpenter and Lemaire, 2004]. The simulated equatorial wave amplitude is shown in Figure $4 \mathrm{~b}$. The peak hiss amplitude does not change much even with a pronounced variation of the plasmapause width $\left(L_{\mathrm{ppw}}=3,2\right.$, $0.7,0.2): 22 \mathrm{pT}\left(G_{p}=1 \mathrm{~dB}\right.$, red), $22 \mathrm{pT}\left(G_{p}=1 \mathrm{~dB}\right.$, green), $19 \mathrm{pT}\left(G_{p}=0 \mathrm{~dB}\right.$, black $)$, and $17 \mathrm{pT}\left(G_{p}=-1 \mathrm{~dB}\right.$, blue $)$. However, the inner peak of the hiss intensity moves toward lower $L$, which enhances the hiss intensity in inner plasmasphere up to one order of magnitude $(\sim 9 \mathrm{~dB}$ enhancement at $L=2.4$ by increasing $L_{\mathrm{ppw}}=0.2$ to $\left.L_{\mathrm{ppw}}=3\right)$. The outer peaks remain at similar locations $3.5<L<4$.

[17] The reason for the inward shift of the peak hiss intensity in the case of an increased plasmapause width is illustrated in Figure 4c by tracing the same source ray in density models with different $L_{\mathrm{ppw}}(=0.7$ black, $=3$ red $)$. The black line in Figure $4 \mathrm{c}$ is identical to that in Figure $3 \mathrm{c}$. The $L_{\mathrm{ppw}}=3.0$ ray (red line) propagates inside the trough region exactly the same way as the $L_{\mathrm{ppw}}=0.7$ ray (black line), but experiences a smoother density gradient associated with wider plasmapause and the wave normal direction rotates more slowly toward $\psi=90^{\circ}$ (reflection). Magnetospheric reflection then occurs at lower $L$-shells, resulting in an equatorial crossing at lower $L$. As a consequence, inner peaks progressively shift Earthward (Figure $4 \mathrm{~b}$ ) as the plasmapause width increases.

[18] As shown above, the location and width of the plasmapause can affect the spatial location of the power deposited by chorus waves on their first equatorial crossing within the plasmasphere. Changes in the plasmapause can also affect the resulting frequency and wave normal angle distribution of hiss. Figure 5 shows the examples of simulated frequency spectrum (Figures 5a, 5c, and $5 \mathrm{e}$ ) and wave normal angle distribution (Figures 5b, 5d, and 5f) for three cases $L_{\mathrm{ppo}}=3.5$ and $L_{\mathrm{ppw}}=0.7$ (Figures $5 \mathrm{a}$ and $5 \mathrm{~b}$ ), the nominal case $L_{\mathrm{ppw}}=4.5$ and $L_{\mathrm{ppw}}=0.7$ (Figures $5 \mathrm{c}$ and $5 \mathrm{~d}$ ), and $L_{\mathrm{ppo}}=4.5$ and $L_{\mathrm{ppw}}=3$ (Figures $5 \mathrm{e}$ and $5 \mathrm{f}$ ). The corresponding density distributions for these three cases are shown in Figures 1a, 1c, and 1e, respectively. For all the three cases the simulated hiss frequency spectrum lies in the typical observed hiss frequency range $200 \mathrm{~Hz}-2 \mathrm{kHz}$, and the high density plasmasphere serves as an excellent cavity for the hiss emission separating it from the chorus emission outside the plasmapause. Although the chorus intensity peak $\left(L_{\text {peak }}=7\right)$ is $3.5 R_{E}$ away from the outer edge of the plasmapause for the case $L_{\mathrm{ppo}}=3.5$, the chorus still contributes to the formation of the plasmaspheric hiss with intensity comparable to that in the case with $L_{\mathrm{ppo}}=4.5$ (compare Figure 5a with Figures 5c and 5e). Comparison of the wave normal distributions with the nominal case (Figure 5d) shows that a contracted plasmasphere (Figure 5b) or wider plasmapause (Figure $5 \mathrm{f}$ ) tends to enhance the hiss wave power near the field-aligned direction and conversely 

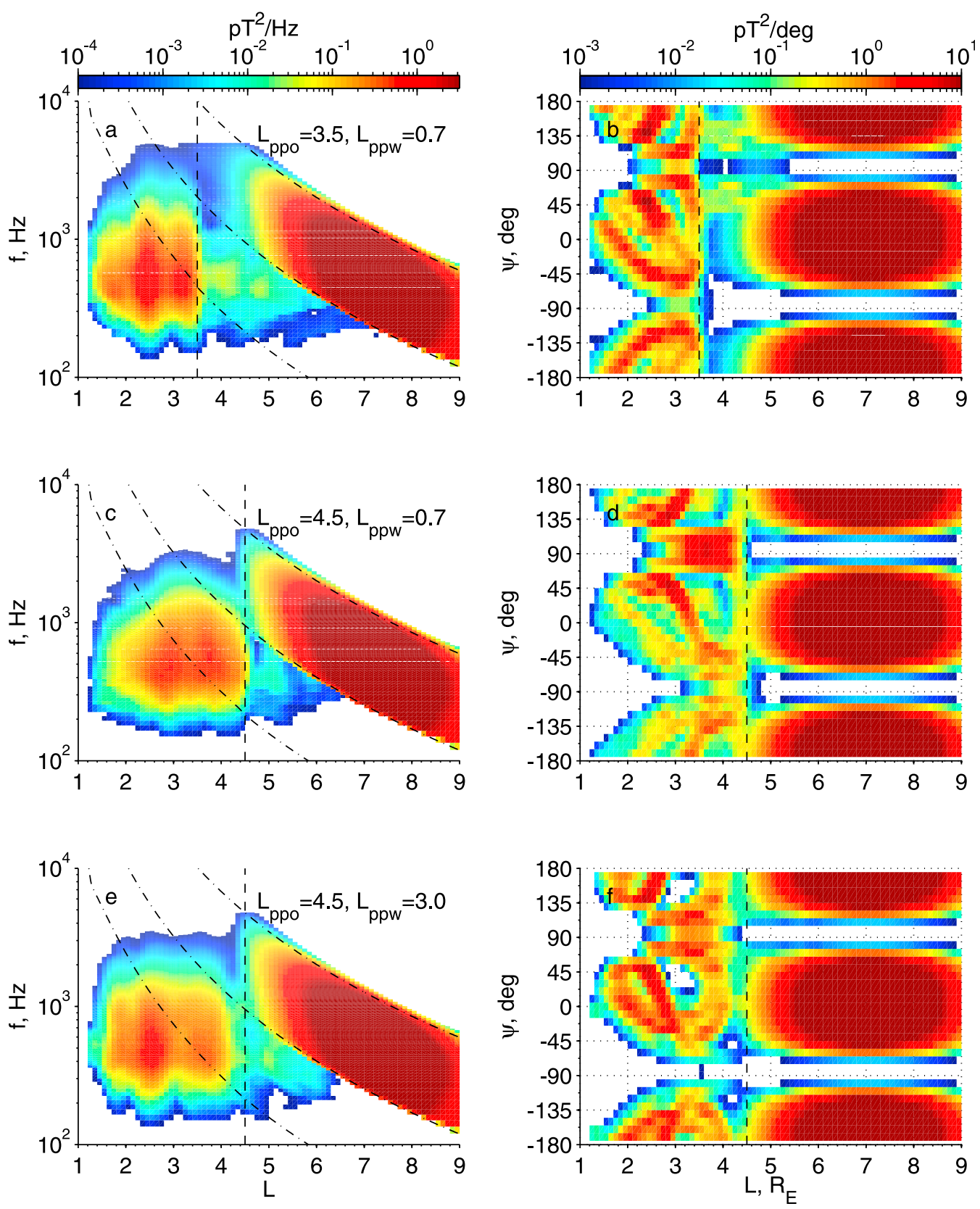

Figure 5. The simulated (a, c, and e) equatorial frequency spectrum and (b, d, and f) wave normal angle distribution using three different plasmapause density models: $L_{\mathrm{ppo}}=3.5$ and $L_{\mathrm{ppw}}=0.7$ (Figures $5 \mathrm{a}$ and $5 \mathrm{~b}$ ), $L_{\mathrm{ppo}}=4.5$ and $L_{\mathrm{ppw}}=0.7$ (Figures $5 \mathrm{c}$ and $5 \mathrm{~d}$ ), and $L_{\mathrm{ppo}}=4.5$ and $L_{\mathrm{ppw}}=3.0$ (Figures $5 \mathrm{e}$ and $5 \mathrm{f}$ ). The vertical dashed lines represent $L=L_{\mathrm{ppo}}$. The three dot-dashed black lines in Figures $5 \mathrm{a}, 5 \mathrm{c}$, and $5 \mathrm{e}$ indicate $0.5 f_{\text {ce }}, 0.1 f_{\text {ce }}$ and $f_{1 \mathrm{hr}}$, from top to bottom.

tends to reduce the portion of the wave power near $90^{\circ}$. This preference for field-aligned waves is as a consequence of the increased possibility that waves experience internal reflections at the plasmapause. Field aligned wave normals near the equator are favored either with a contracted plasmasphere (Figure 5b) or due to an increased region with large inward density gradient (Figure 5f). The case with large plasmapause width $\left(L_{\mathrm{ppw}}=3\right)$ also reveals fine structures of the frequency and especially the wave normal distribution inside the plasmapause boundary layer (Figures $5 \mathrm{e}$ and $5 \mathrm{f}$ ), with nearly uniform wave normal angle distribution except for a gap at $\psi \sim \pm 90^{\circ}$ at the inner layer of the plasmapause. The hiss emission tends to be more confined to the high density region $L<4\left(>\sim 70 \mathrm{~cm}^{-3}\right)$, leaving a much weaker emission at the outer layer of plasmapause boundary $(4<L<4.5)$.

\subsection{Trough Density Distribution}

[19] Hiss inside the plasmasphere is also controlled by the density distribution in the trough, where chorus is generated. Two parameters, $\beta$ and $n_{0 \text { tr }}$, control the trough density distribution near the equatorial region and along field lines at higher latitudes respectively. In this section, we will 

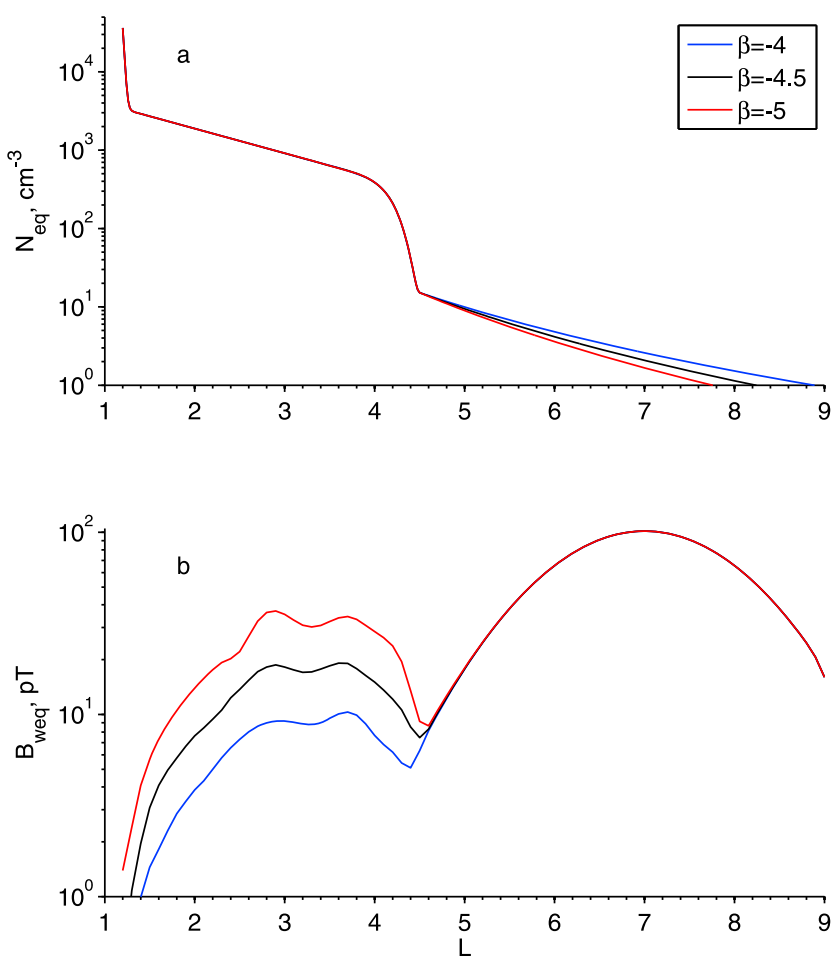

Figure 6. Similar to Figures $3 a$ and $3 b$ except varying the trough density slope index $\beta$.

investigate the effects of $\beta$ and $n_{0 \text { tr }}$ on the resulting distribution of hiss.

[20] The response of hiss to the equatorial trough density distribution is investigated by varying the trough equatorial density slope $\beta$ while keeping the density at $L \leq L_{\mathrm{ppo}}$, and in the trough at low altitude the same. Figure 6 a shows the resulting equatorial density distributions. Although the difference between the equatorial density for $\beta=-4$ (blue line) and $\beta=-5$ (red line) is small $\left(<\sim 1 \mathrm{~cm}^{-3}\right)$, the changes in hiss peak amplitude are significant (Figure 6b): $\sim 10 \mathrm{pT}$ (blue), $19 \mathrm{pT}$ (black) and $37 \mathrm{pT}$ (red), corresponding to $G_{p}=$ $-5 \mathrm{~dB}, 0 \mathrm{~dB},+6 \mathrm{~dB}$. The enhancement of equatorial hiss intensity occurs throughout the entire $L$ range inside the plasmasphere, as $|\beta|$ increases. The inner hiss peak locations for all three cases are about the same, indicating that the value of $\beta$ in the trough has little effect on the first equatorial crossing of rays after entry into the plasmasphere.

[21] Figure 7a shows the behavior of the nominal ray to density models with different $\beta$. For $\lambda<10^{\circ}$ the raypaths for all three cases are about the same. The raypaths begin to deviate from each other at higher latitudes: for lower value of $\beta(=-5$, red line) the ray propagates to lower $L$-shells than the ray with higher $\beta$ ( $=-4$, blue line). This deviation of the raypaths is a consequence of the increased Earthward turning of the wave vector associated with increased density gradient in the trough. The deviation becomes larger as rays propagate over longer distance, since the amount of Earthward turning is accumulated along the raypaths. For the density model with $\beta=-4$ (blue line), the nominal ray never reaches the plasmapause because it experiences insufficient Earthward turning. For lower $\beta$ (black and red lines) the Earthward turning is more pronounced and thus rays enter into the plasmasphere. The ray with the lowest $\beta$ (red line) reaches the plasmapause at lower latitudes, and crosses the equator inside the plasmasphere at higher $L$. Figure $7 \mathrm{~b}$ shows the latitude at which chorus rays first reach the plasmapause $(L=$ $L_{\text {ppo }}$ ) as a function of initial chorus source wave normal angle for three different trough density models. The dependence of the rays entering the plasmapause (black line in Figure 7b) in the nominal density distribution is also illustrated by Figure 2. Chorus waves that are unable to enter the plasmasphere include the rays with $\psi_{i} \leq-68^{\circ}$ (Figure 2a) and $\psi_{i} \geq-34^{\circ}$ (Figure 2d). All chorus rays with $-67^{\circ} \leq \psi_{i} \leq$ $q-35^{\circ}$ (Figures $2 \mathrm{~b}$ and $2 \mathrm{c}$ ) can contribute to the intensity of plasmaspheric hiss. However, because the intensity of lower band chorus tends to peaks in the field-aligned direction [ $\mathrm{Li}$ et al., 2011], the largest contribution to hiss intensity will come from chorus with smaller $\left|\psi_{i}\right|$, namely those with $\psi_{i}$ just below $-35^{\circ}$ for the case illustrated. The hiss intensity increases as $\beta$ decreases, primarily because the number of rays entering the plasmasphere increases, especially those with less negative wave normal angle and thus higher wave power. As shown in Figure 7b, the least negative wave normal for waves entering the plasmasphere increases from $-42^{\circ}$, to $-35^{\circ}$, to $-26^{\circ}$, as $\beta$ decreases from -4 , to -4.5 and to -5 .

[22] We also investigate the effect of varying the trough density gradient at low altitude by varying $n_{0 t r}$ from $500 \mathrm{~cm}^{-3}$, $2000 \mathrm{~cm}^{-3}$, to $5000 \mathrm{~cm}^{-3}$, while keeping the equatorial trough density distribution and the plamasphere density distribution the same. The value of $n_{0 \text { tr }}$, varying widely from a few $100 \mathrm{~s}$ to $10^{4} \mathrm{~cm}^{-3}$ [Kitamura et al., 2009], is strongly dependent on the amount of solar radiation absorption, which depends on local times and seasons. Although $n_{0 \text { tr }}$ directly controls the latitudinal variation along field lines, the quantity which controls the accessibility of chorus rays from outside to inside the plasmasphere is the trough slope index $T=\nabla_{\perp} N_{e}\left(L R_{E} / N_{e}\right)$, where $\perp$ denotes the component of density gradient perpendicular to the ambient magnetic field, and $T=\beta$ at the equator. $T$ is a measure of the density gradient in the perpendicular direction and thus is closely related to the turning of chorus ray across magnetic fields. Figure 8 a shows the dependence of $T$ on $L$ at $\lambda=30^{\circ}$ for three different values of $n_{0 \mathrm{tr}}$. For the prescribed three cases, $|T|$ remains the same in the plasmasphere but decreases in the trough as $n_{0 \text { tr }}$ increases. The simulated equatorial hiss wave power for these three cases is shown in Figure 8b. Clearly, the decrease of $|T|$ associated with an increase in $n_{0 \text { tr }}$ results in a decrease in hiss intensity, $G_{p}=0 \mathrm{~dB}$ (nominal case), $-4 \mathrm{~dB}$ (blue) and $-8 \mathrm{~dB}$ (red). The reason for decreases in the wave amplitude of hiss is that increasing $n_{0 \text { tr }}$ reduces the amount of chorus power that enters the plasmasphere. The effect of $n_{0 \text { tr }}$ is similar to that of $\beta$ except that $\beta$ controls the equatorial trough density gradient and $n_{0 \text { tr }}$ controls the trough density gradient off the equator. The behavior of a nominal ray in density distributions with different $n_{0 \text { tr }}$ is compared in Figure 9a, showing that the nominal ray in high $n_{0 \text { tr }}$ (red line) is subject to less Earthward turning and can not access to the plasmasphere. As $n_{0 \text { tr }}$ increases from $500 \mathrm{~cm}^{-3}$ to $5000 \mathrm{~cm}^{-3}$, the least negative wave normal angle of chorus which gains access to the plasmasphere decreases from $-35^{\circ}$ to $\sim-45^{\circ}$ (Figure 9b). More chorus rays can therefore enter the plasmasphere for larger $|T|$ (or smaller $n_{0 \text { tr }}$ ).

[23] Figure 10 shows the frequency and wave normal angle spectrum from three runs with different trough density 

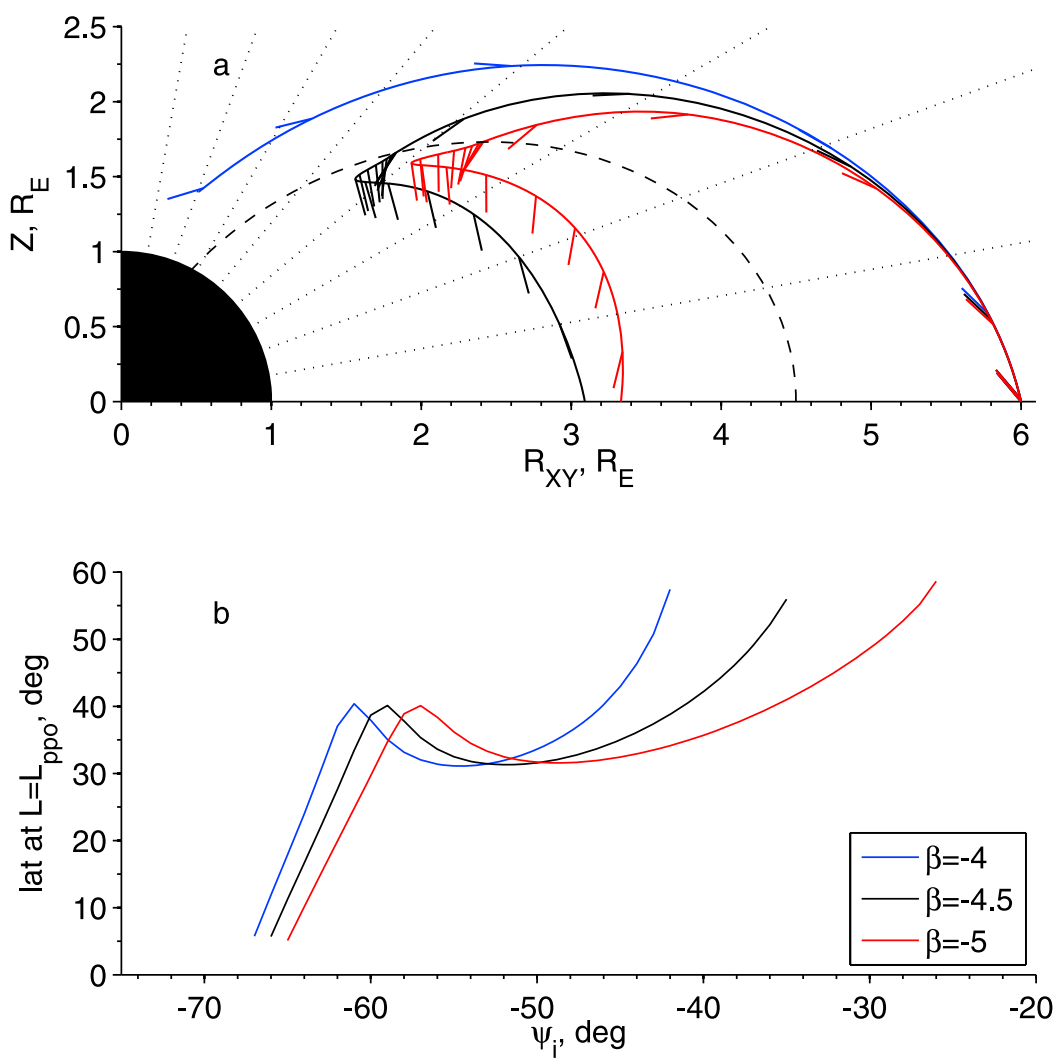

Figure 7. (a) Example of rays launched at $L_{i}=6$ with $\left(f / f_{\text {ce }}\right)_{i}=0.15$ and $\psi_{i}=-40^{\circ}$, in density models with different values of $\beta$. The field line with $L=4.5$ is shown in black dashed lines. Eight dotted lines represent constant latitudes from $10^{\circ}$ to $80^{\circ}$ in $10^{\circ}$ increments. The short straight line segments starting from the ray trajectories indicate the direction of the wave vector during the propagation. (b) The latitude of chorus entry into the plasmasphere $\left(L=L_{\mathrm{ppo}}\right)$ for rays launched at $L=6$ with $f=0.15 f_{\text {ce }}$, as a function of initial wave normal angles $\psi_{i}$, in density models with different values of $\beta$.

distributions, $\beta=-5$ and $n_{0 \mathrm{tr}}=500 \mathrm{~cm}^{-3}$ (Figures 10a and $10 \mathrm{~b})$, the nominal case $\beta=-4.5$ and $n_{0 \operatorname{tr}}=500 \mathrm{~cm}^{-3}$ (Figures $10 \mathrm{c}$ and $10 \mathrm{~d}$ ), and $\beta=-4.5$ and $n_{0 \mathrm{tr}}=5000 \mathrm{~cm}^{-3}$ (Figures 10e and 10f). The corresponding density distributions for these three cases are shown in Figures 1b, 1d, and 1f, respectively. Despite the much stronger hiss intensity in the $\beta=-5$ case and much weaker hiss intensity in the $n_{0 \text { tr }}=$ $5000 \mathrm{~cm}^{-3}$ case, compared with the nominal case, the shapes of the hiss frequency and spatial distributions are remarkably similar. The wave normal angle distributions also have similar characteristics.

\section{Principal Conclusions}

[24] In paper I, we investigated the detailed response of the hiss intensity to changes in the chorus distribution, namely to variations in $L$-shell, wave normal angle $\psi$ and wave frequency, in a model magnetosphere with prescribed cold and suprathermal electron distributions of $\mathrm{MLT}=10$. The present analysis has focused on examining the effects of wave propagation, due to the variation of plasmapause boundary and trough densities, on the hiss intensity distribution in the equatorial plasmasphere of MLT $=10$. Our principle conclusions are as follows.

[25] 1. The location of the plasmapause boundary does not significantly affect the resulting peak hiss intensity $(<\mathrm{a}$ few
$\mathrm{dB}$ ) but does regulate the distribution of hiss intensity inside the plasmasphere. A wider plasmapause boundary and a contracted plasmasphere tends to shift the hiss intensity peak toward lower $L$ and also increases the fraction of the hiss wave power near the field-aligned direction.

[26] 2. The density distribution in the plasma trough significantly affects the amount of chorus power deposited into the plasmasphere. A trough with steeper density slopes near the equator or lower trough density at low altitudes can increase peak hiss intensity by up to $\sim 10 \mathrm{~dB}$.

[27] 3. Our simulated hiss emission is well confined to the high density plasmasphere regardless of the shape of plasmapause, consistent with observations.

[28] 4. Regardless of the variability of plasmapause and trough density distribution, the simulated hiss frequency distribution is primarily confined to the frequency range $200 \mathrm{~Hz}-2 \mathrm{kHz}$, consistent with prior observations.

[29] 5. The relative peak amplitude of our simulated hiss, compared to the chorus source, is weaker than observed, indicating the necessity of some internal amplification inside the plasmasphere.

\section{Discussion}

[30] The cold plasma density distribution, which controls the propagation of chorus waves, is important for modeling 

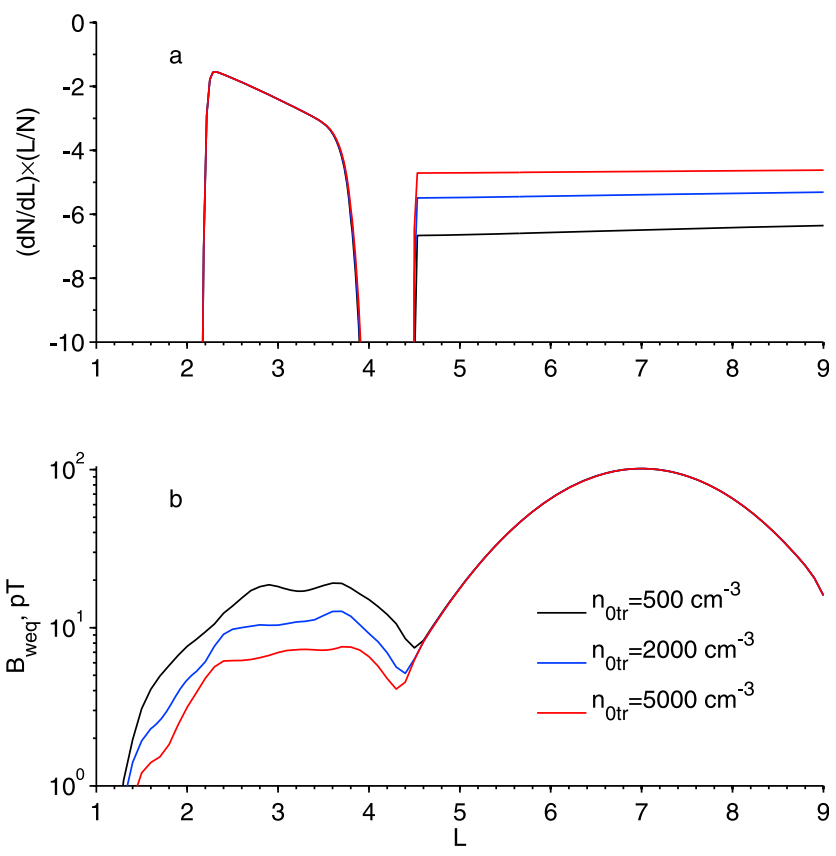

Figure 8. (a) The values of $\nabla_{\perp} N \times L R_{E} / N$ at a latitude $\lambda=30^{\circ}$ in density models with varying $n_{0 \mathrm{tr}}$, where $\perp$ denotes direction perpendicular to ambient magnetic field. (b) The corresponding equatorial wave amplitude distribution.

the hiss wave power inside the plasmasphere. In our present modeling, ray tracing is performed using a statistical cold plasma density distribution. However, the dynamics and structure of the plasma density distribution shows strong dependencies on local time, the seasons, the level of geomagnetic activity and the phase of geomagnetic storms [e.g., Carpenter and Park, 1973; Grebowsky, 1970; Goldstein et al., 2002; Kitamura et al., 2009; Fu et al., 2010], primarily involving convection drift due to corotating and convection electric field, dayside outflow from the ionosphere associated with the strength of solar radiation, nightside drainage into ionosphere and afternoon drainage plume loss to the magnetopause. The trough density distribution could also vary on timescales of days associated with slow ionospheric outflow [Harris, 1974] or on a timescale of hours associated with the storm time convection, which might also turn on or off the accessibility of chorus wave power to the plasmasphere depending on the slope of trough density with respect to $L$. Although the statistical trough density variation has been studied previously, the trough density distribution, especially the variation of the trough density slope, in response to storms is still poorly understood. The plasmapause boundary could influence the strength of hiss intensity near the field-aligned direction. As plasmapause moves to lower $L$ during storm times, or as its width increases, the fieldaligned component of hiss tends to increase, which is not only important for possible wave amplification inside the plasmasphere, but can also increase the effectiveness of radiation belt electron loss, whose timescale decreases as hiss emission power concentrates at low wave normal angles [Meredith et al., 2006]. Formation of the storm time plume and its subsequent evolution can introduce new azimuthal propagation characteristics of the hiss [e.g., Chen et al., 2009a], associated with the azimuthal density gradients.
Fine scale structure such as density crest and trough ducts, density fluctuations inside the plume and near the plasmapause might also introduce fine structure in the plasmaspheric hiss wave power distribution.

[31] Although there can be variability of plasmaspheric hiss due to changes in the chorus source characteristics (see paper I) and due to the variability of plasma density distribution, the resulting hiss intensity is still weaker than the observed value. Cyclotron resonant wave amplification inside the plasmasphere, especially in the outer plasmasphere region where plasma sheet electrons might diffuse across their Alfven layer [ $\mathrm{Li}$ et al., 2010], could be important to account for the intensity discrepancy. Our current modeling suggests that the hiss formation is primarily due to the evolution of external generated chorus waves, but also requires additional internal amplification inside the plasmasphere. The process of internal amplification may also modify the distribution of the hiss wave power over the wave frequency, wave normal angle and spatial location, because of preferential amplification of those rays that are able to pass through the outer plasmasphere with nearly field-aligned wave normal.

[32] The high density plasmasphere $\left(>70 \mathrm{~cm}^{-3}\right)$ appears to provide excellent confinement for plasmaspheric hiss, regardless of the shape of plasmapause and even without a sharp plasmapause boundary. However, the shape of the plasmapause regulates the way chorus power is distributed inside the plasmasphere, and should be treated as a boundary layer with structures rather than a strict boundary in terms of linking chorus and hiss emission. Although increasing the plasmapause width produces a smooth transition between the plasmasphere and trough density, it should be noted that our current density model still requires an existence of the outer edge of plasmapause, beyond which the trough density distribution remains unchanged. As a consequence, the increase in the plasmapause width does not change the amount of
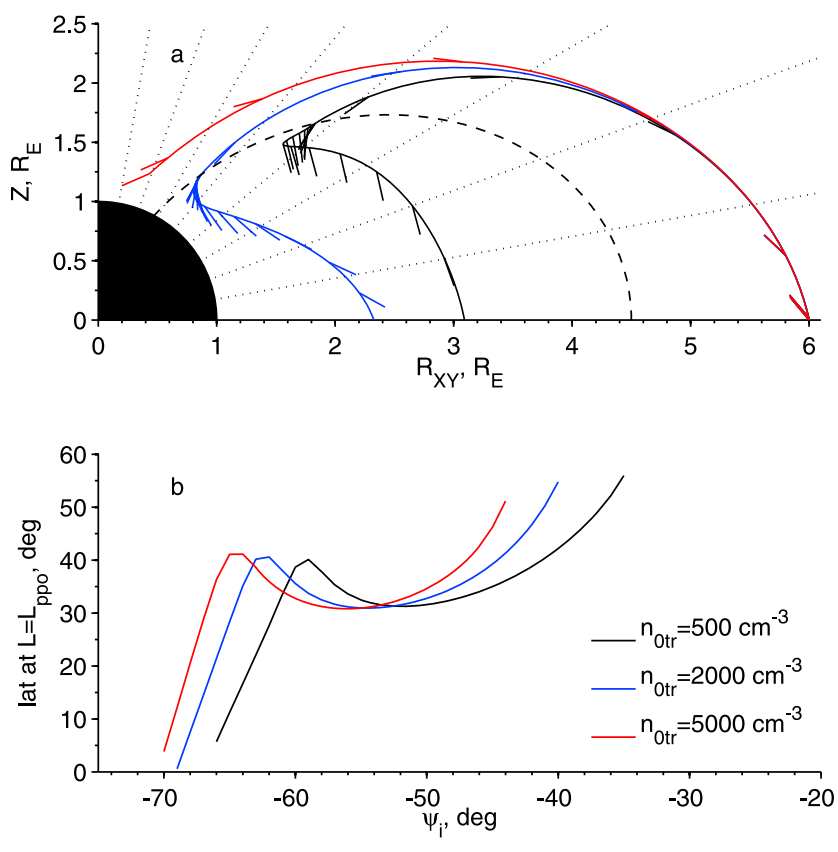

Figure 9. Similar to Figure 7 except for different values of trough base density $n_{0 \text { tr. }}$. 

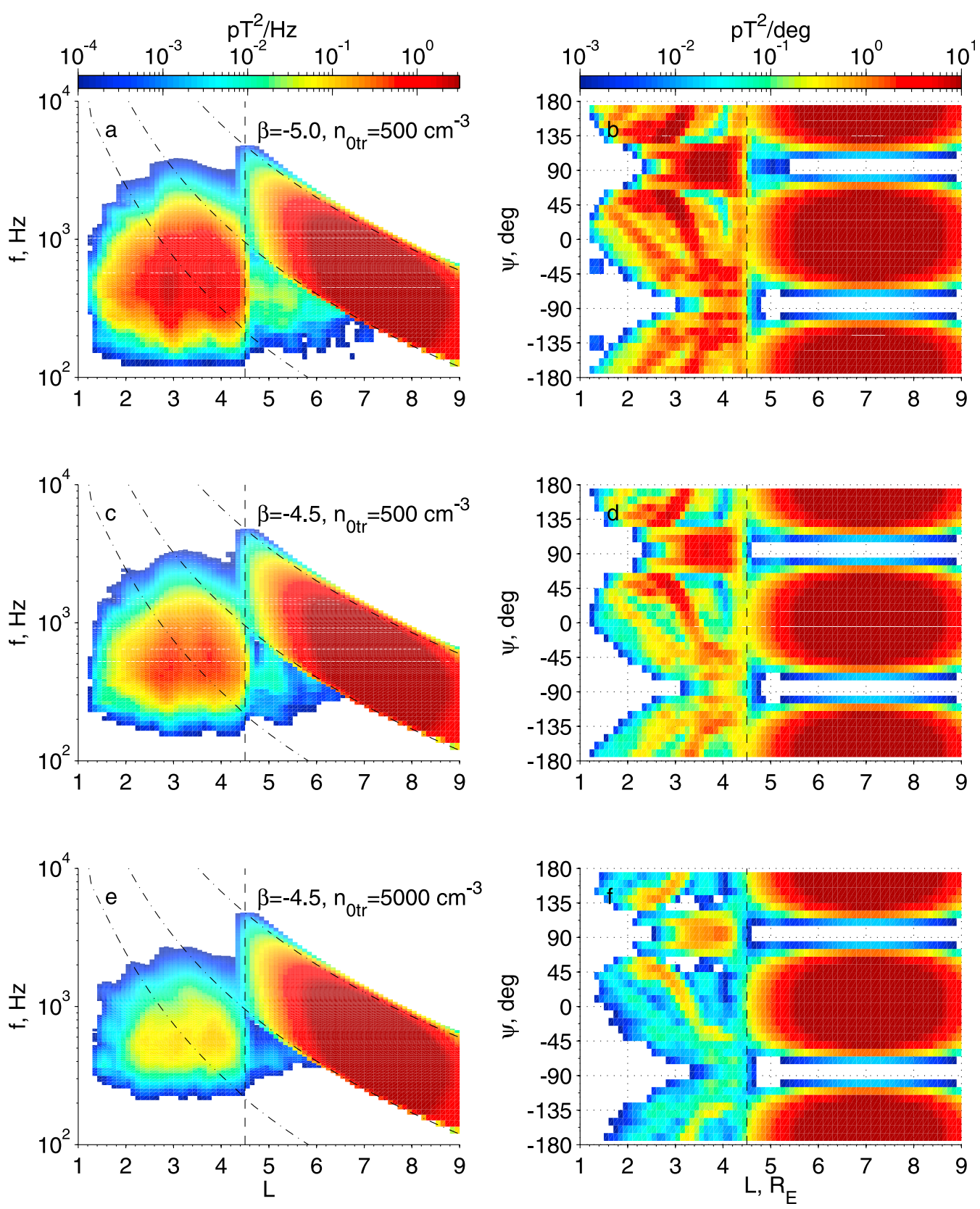

Figure 10. Similar to Figure 5 except for three different trough density models: (a and b) $\beta=-5$ and $n_{0 \text { tr }}=500 \mathrm{~cm}^{-3}$, (c and d) $\beta=-4.5$ and $n_{0 \text { tr }}=500 \mathrm{~cm}^{-3}$, and (e and f) $\beta=-4.5$ and $n_{0 \text { tr }}=5000 \mathrm{~cm}^{-3}$.

wave power reaching the outer edge of plasmapause, and only regulates the wave power distribution inside the plasmapause. However, the density model with large plasmapause width may not be well representative of realistic plasmasphere boundary layer where there is no strict boundary between them. Therefore, the dynamic evolution and local time dependence of plasmapause layer structure itself should also be considered in future hiss modeling.

[33] We have identified the dominant parameters related to the chorus source distribution (paper I) and the cold plasma density distribution in the present study that could affect hiss intensity inside the plasmasphere. The importance of each parameter is evaluated by varying one parameter at a time while keeping the others unchanged. However, these parameters are not unrelated. The plasma density distribution, including the plasmapause and plasma trough, shows strong local time and activity dependencies, and the chorus distribution also has such dependencies. For example, the chorus peak location varies with local time from relatively low $L$ on the nightside, increasing as local time increases, to $L \sim 8$ near noon [Li et al., 2009]. However, the plasmapause location shows a similar dependence, i.e., increasing from night to noon [Carpenter and Anderson, 1992]. Understanding the local time favorable for chorus power entry into the plasmasphere requires modeling the hiss spectrum by varying both chorus peak location and plasmapause location simultaneously. There is important local time dependence of other important conditions, such as the trough density slope. 
To understand the global distribution of hiss intensity and the optimal source of chorus that contributes most to the hiss, the local time and storm time dependence of various combination of these parameters will be required in future modeling.

[34] Acknowledgments. This research was supported by NSF grant AGS-0840178 and NASA grant NNX08A135G. We acknowledge NASA contract NAS5-020P9 and V. Angelopoulos for use of data from the THEMIS mission, A. Roux and O. Le Contel for use of SCM data. The authors also thank World Data Center for Geomagnetism, Kyoto for providing the $\mathrm{AE}$ index.

[35] Robert Lysak thanks the reviewers for their assistance in evaluating this paper.

\section{References}

Abel, B., and R. M. Thorne (1998a), Electron scattering loss in Earth's inner magnetosphere: 1. Dominant physical processes, J. Geophys. Res., 103, 2385-2396, doi:10.1029/97JA02919.

Abel, B., and R. M. Thorne (1998b), Electron scattering loss in Earth's inner magnetosphere: 2. Sensitivity to model parameters, J. Geophys. Res., 103, 2397-2408, doi:10.1029/97JA02920.

Albert, J. M. (2005), Evaluation of quasi-linear diffusion coefficients for whistler mode waves in a plasma with arbitrary density ratio, J. Geophys. Res., 110, A03218, doi:10.1029/2004JA010844.

Bortnik, J., R. M. Thorne, and N. P. Meredith (2008), The unexpected origin of plasmaspheric hiss from discrete chorus emissions, Nature, 452, 62-66, doi:10.1038/nature06741.

Bortnik, J., W. Li, R. M. Thorne, V. Angelopoulos, C. Cully, J. Bonnell, O. Le Contel, and A. Roux (2009), An observation linking the origin of plasmaspheric hiss to discrete chorus emissions, Science, 324, 775-778, doi:10.1126/science.1171273.

Bortnik, J., L. Chen, W. Li, R. M. Thorne, and R. B. Horne (2011a), Modeling the evolution of chorus waves into plasmaspheric hiss, J. Geophys. Res., 116, A08221, doi:10.1029/2011JA016499.

Bortnik, J., L. Chen, W. Li, R. M. Thorne, N. P. Meredith, and R. B. Horne (2011b), Modeling the wave power distribution and characteristics of plasmaspheric hiss, J. Geophys. Res., 116, A12209, doi:10.1029/ 2011JA016862.

Carpenter, D. L., and R. R. Anderson (1992), An ISEE/Whistler model of equatorial electron density in the magnetosphere, J. Geophys. Res., 97(A2), 1097-1108.

Carpenter, D., and J. Lemaire (2004), The plasmasphere boundary layer, Ann. Geophys., 22, 4291-4298, doi:10.5194/angeo-22-4291-2004.

Carpenter, D. L., and C. G. Park (1973), On what ionospheric workers should know about the plasmapause-plasmasphere, Rev. Geophys., 11, 133-154.

Chappell, C. R., K. K. Harris, and G. W. Sharp (1970), A study of the influence of magnetic activity on the location of the plasmapause as measured by OGO 5, J. Geophys. Res., 75, 50-56, doi:10.1029/ JA075i001p00050.

Chen, L., J. Bortnik, R. M. Thorne, R. B. Horne, and V. K. Jordanova (2009a), Three-dimensional ray tracing of VLF waves in a magnetospheric environment containing a plasmaspheric plume, Geophys. Res. Lett., 36, L22101, doi:10.1029/2009GL040451.

Chen, L., R. M. Thorne, and R. B. Horne (2009b), Simulation of EMIC wave excitation in a model magnetosphere including structured high-density plumes, J. Geophys. Res., 114, A07221, doi:10.1029/2009JA014204.

Chen, L., R. M. Thorne, V. K. Jordanova, C.-P. Wang, M. Gkioulidou, L. Lyons, and R. B. Horne (2010), Global simulation of EMIC wave excitation during the 21 April 2001 storm from coupled RCM-RAMHOTRAY modeling, J. Geophys. Res., 115, A07209, doi:10.1029/ 2009JA015075.

Chen, L., J. Bortnik, R. M. Thorne, W. Li, and R. B. Horne (2012), Modeling the properties of plasmaspheric hiss: 1 . Dependence on chorus wave emission, J. Geophys. Res., 117, A05201, doi:10.1029/2011JA017201.

Denton, R. E., J. Goldstein, and J. D. Menietti (2002), Field line dependence of magnetospheric electron density, Geophys. Res. Lett., 29(24), 2205, doi:10.1029/2002GL015963.

Fu, H. S., J. Tu, J. B. Cao, P. Song, B. W. Reinisch, D. L. Gallagher, and B. Yang (2010), IMAGE and DMSP observations of a density trough inside the plasmasphere, J. Geophys. Res., 115, A07227, doi:10.1029/ 2009JA015104.

Golden, D. I., M. Spasojević, F. R. Foust, N. G. Lehtinen, N. P. Meredith, and U. S. Inan (2010), Role of the plasmapause in dictating the ground accessibility of ELF/VLF chorus, J. Geophys. Res., 115, A11211, doi:10.1029/2010JA015955.
Goldstein, J., R. W. Spiro, P. H. Reiff, R. A. Wolf, B. R. Sandel, J. W. Freeman, and R. L. Lambour (2002), IMF-driven overshielding electric field and the origin of the plasmaspheric shoulder of May 24, 2000, Geophys. Res. Lett., 29(16), 1819, doi:10.1029/2001GL014534.

Grebowsky, J. M. (1970), Model study of plasmapause motion, J. Geophys. Res., 75, 4329-4333, doi:10.1029/JA075i022p04329.

Green, J. L., D. A. Gurnett, and S. D. Shawhan (1977), The angular distribution of auroral kilometric radiation, J. Geophys. Res., 82, 1825-1838, doi:10.1029/JA082i013p01825.

Harris, K. K. (1974), The measurement of cold ion densities in the plasma trough, J. Geophys. Res., 79, 4654-4660, doi:10.1029/JA079i031p04654.

Horne, R. B. (1989), Path-integrated growth of electrostatic waves: The generation of terrestrial myriametric radiation, J. Geophys. Res., 94(A7), 8895-8909.

Horne, R. B., and R. Thorne (1993), On the preferred source location for the convective amplification of ion cyclotron waves, J. Geophys. Res., 98(A6), 9233-9247.

Jordanova, V. K., R. M. Thorne, W. Li, and Y. Miashi (2010), Excitation of whistler-mode chorus from global ring current simulations, J. Geophys. Res., 115, A00F10, doi:10.1029/2009JA014810.

Kasahara, Y., H. Kenmochi, and I. Kimura (1994), Propagation characteristics of the ELF emissions observed by the satellite Akebono in the magnetic equatorial region, Radio Sci., 29, 751-767, doi:10.1029/ 94RS00445.

Kitamura, N., A. Shinbori, Y. Nishimura, T. Ono, M. Iizima, and A. Kumamoto (2009), Seasonal variations of the electron density distribution in the polar region during geomagnetically quiet periods near solar maximum, J. Geophys. Res., 114, A01206, doi:10.1029/2008JA013288.

Li, W., Y. Y. Shprits, and R. M. Thorne (2007), Dynamic evolution of energetic outer zone electrons due to wave-particle interactions during storms, J. Geophys. Res., 112, A10220, doi:10.1029/2007JA012368.

Li, W., R. M. Thorne, V. Angelopoulos, J. Bortnik, C. M. Cully, B. Ni, O. LeContel, A. Roux, U. Auster, and W. Magnes (2009), Global distribution of whistler-mode chorus waves observed on the THEMIS spacecraft, Geophys. Res. Lett., 36, L09104, doi:10.1029/2009GL037595.

Li, W., R. M. Thorne, J. Bortnik, Y. Nishimura, V. Angelopoulos, L. Chen, J. P. McFadden, and J. W. Bonnell (2010), Global distributions of suprathermal electrons observed on THEMIS and potential mechanisms for access into the plasmasphere, J. Geophys. Res., 115, A00J10, doi:10.1029/2010JA015687.

Li, W., J. Bortnik, R. M. Thorne, and V. Angelopoulos (2011), Global distribution of wave amplitudes and wave normal angles of chorus waves using THEMIS wave observations, J. Geophys. Res., 116, A12205, doi:10.1029/2011JA017035.

Lorentzen, K. R., J. B. Blake, U. S. Inan, and J. Bortnik (2001), Observations of relativistic electron microbursts in association with VLF chorus, J. Geophys. Res., 106, 6017-6028, doi:10.1029/2000JA003018.

Lyons, L. R., and R. M. Thorne (1973), Equilibrium structure of radiation belt electrons, J. Geophys. Res., 78, 2142-2149, doi:10.1029/ JA078i013p02142.

Lyons, L. R., R. M. Thorne, and C. F. Kennel (1972), Pitch-angle diffusion of radiation belt electrons within the plasmasphere, J. Geophys. Res., 77, 3455-3474, doi:10.1029/JA077i019p03455.

Meredith, N. P., R. B. Horne, S. A. Glauert, R. M. Thorne, D. Summers, J. M. Albert, and R. R. Anderson (2006), Energetic outer zone electron loss timescales during low geomagnetic activity, J. Geophys. Res., 111, A05212, doi:10.1029/2005JA011516.

Moldwin, M. B., L. Downward, H. K. Rassoul, R. Amin, and R. R. Anderson (2002), A new model of the location of the plasmapause: CRRES results, J. Geophys. Res., 107(A11), 1339, doi:10.1029/2001JA009211.

Poulter, E. M., W. Allan, J. G. Keys, and E. Nielsen (1984), Plasmatrough ion mass densities determined from ULF pulsation eigenperiods, Planet. Space Sci., 32, 1069-1078, doi:10.1016/0032-0633(84)90132-6.

Reinisch, B. W., M. B. Moldwin, R. E. Denton, D. L. Gallagher, H. Matsui, V. Pierrard, and J. Tu (2009), Augmented empirical models of plasmaspheric density and electric field using IMAGE and CLUSTER data, Space Sci. Rev., 145, 231-261, doi:10.1007/s11214-008-9481-6.

Russell, C. T., R. E. Holzer, and E. J. Smith (1969), OGO 3 observations of ELF noise in the magnetosphere: 1 . Spatial extent and frequency of occurrence, J. Geophys. Res., 74, 755-777, doi:10.1029/JA074i003p00755.

Sandel, B. R., J. Goldstein, D. L. Gallagher, and M. Spasojević (2003), Extreme Ultraviolet Imager observations of the structure and dynamics of the plasmasphere, Space Sci. Rev., 109, 25-46, doi:10.1023/B: SPAC.0000007511.47727.5b.

Sheeley, B. W., M. B. Moldwin, H. K. Rassoul, and R. R. Anderson (2001), An empirical plasmasphere and trough density model: CRRES observations, J. Geophys. Res., 106(A11), 25,631-25,641. 
Singh, A. K., R. P. Singh, and D. Siingh (2011), State studies of Earth's plasmasphere: A review, Planet. Space Sci., 59, 810-834, doi:10.1016/ j.pss.2011.03.013

Spasojević, M., J. Goldstein, D. L. Carpenter, U. S. Inan, B. R. Sandel, M. B. Moldwin, and B. W. Reinisch (2003), Global response of the plasmasphere to a geomagnetic disturbance, J. Geophys. Res., 108(A9), 1340, doi:10.1029/2003JA009987.

Summers, D., B. Ni, N.P. Meredith, R. B.Horne, R. M. Thorne, M. B. Moldwin, and R. R. Anderson (2008), Electron scattering by whistler-mode ELF hiss in plasmaspheric plumes, J. Geophys. Res., 113, A04219, doi:10.1029/ 2007JA012678

Thorne, R. M., E. J. Smith, R. K. Burton, and R. E. Holzer (1973), Plasmaspheric hiss, J. Geophys. Res., 78, 1581-1596, doi:10.1029/ JA078i010p01581.

Thorne, R. M., T. P. O’Brien, Y. Y. Shprits, D. Summers, and R. B. Horne (2005), Timescale for $\mathrm{MeV}$ electron microburst loss during geomagnetic storms, J. Geophys. Res., 110, A09202, doi:10.1029/2004JA010882.
Wang, C., Q. Zong, F. Xiao, Z. Su, Y. Wang, and C. Yue (2011), The relations between magnetospheric chorus and hiss inside and outside the plasmasphere boundary layer: Cluster observation, J. Geophys. Res., 116, A07221, doi:10.1029/2010JA016240.

Xiao, F., L. Chen, H. Zheng, and S. Wang (2007), A parametric ray tracing study of superluminous auroral kilometric radiation wave modes, J. Geophys. Res., 112, A10214, doi:10.1029/2006JA012178.

Xiao, F., Z. Su, H. Zheng, and S. Wang (2009), Modeling of outer radiation belt electrons by multidimensional diffusion process, J. Geophys. Res., 114, A03201, doi:10.1029/2008JA013580.

J. Bortnik, L. Chen, W. Li, and R. M. Thorne, Department of Atmospheric Sciences, University of California, Los Angeles, CA 90024, USA (clj@atmos.ucla.edu)

R. B. Horne, British Antarctic Survey, Natural Environment Research Council, Cambridge CB3 0ET, UK. 